Article

\title{
Application of the Random Decrement Technique in Damage Detection under Moving Load
}

\author{
Hadi Kordestani ${ }^{(1)}$, Yi-Qiang Xiang * (1), Xiao-Wei Ye and Ya-Kun Jia \\ College of Civil Engineering and Architecture, Zhejiang University, Hangzhou 310058, China; \\ eng.kordestani@gmail.com (H.K.); cexwye@zju.edu.cn (X.-W.Y.); jiayakun123@126.com (Y.-K.J.) \\ * Correspondence: xiangyiq@zju.edu.cn; Tel.: +86-571-8820-8700
}

Received: 11 April 2018; Accepted: 6 May 2018; Published: 9 May 2018

\begin{abstract}
This paper employs the random decrement technique as an output-only method to detect damage from the acceleration signals under a moving load. The random decrement technique is an especial averaging method that produces Random Decrement Signatures (RDS). For this purpose, Arias Intensity (AI) was employed to calculate the energy content of each RDS and substitute each acceleration signal by a scalar invariant value. Normalizing AIs, all RDSs were then updated so as to show a unique energy along the undamaged structure. Once the normalizing factor was computed for the intact structure, the damage was determined by the absolute difference of normalized AIs obtained from each individual RDS along the structure simultaneously. To verify the proposed method, two experimental models of a simply supported beam and a scaled arch bridge were developed under a moving load (vehicle simulation), and acceleration data were recorded. The results of laboratory models proved that the RDSs can accurately detect the damage location using the normalized AI without applying any further frequency filtering. This method needs neither the damage location nor modal parameters in advance, and could properly work in a noisy environment as well.
\end{abstract}

Keywords: random decrement technique; acceleration data; moving load; damage detection; Arias intensity

\section{Introduction}

Generally, modal parameters are identified by measuring input excitations and output responses. These modal parameters are then used as damage indicators in the damage detection process. For simplicity, it is assumed that if the input excitation is considered as zero, the output response behaves as a free response [1]. There are situations in which inputs come from ambient or random excitations and cannot be ignored. In such cases, it is necessary to use output-only modal identification methods. However, these types of methods also have some limitations. One of the common drawbacks of output-only methods is considering the input as zero-mean and random white noise.

Utilizing acceleration data to detect the damage location could effectively decrease the cost of Structural Health Monitoring (SHM). Accelerometers can be implemented in any desired location of structure to record the acceleration response with a wide range of frequencies. Generally, SHM methods using acceleration data can be categorized into four groups: 1-transformer-based methods, such as Wavelet or Hilbert-Huang transformers [2-7]; 2-averaging-based methods, such as Random Decrement (RD) or Moving average based approaches [8-11]; 3-filtering-based methodologies, such as Kalman filter [12,13]; and, finally, 4-source separation methods such as Blind Source Separation approach [14-17]. This paper presents a RD-based approach that belongs to the second group.

The RD technique is one of the promising output-only time-domain methods introduced by Cole in 1968 [18]. Since then, the RD technique has been received a large amount of attention in Structural Health Monitoring (SHM) when a complete knowledge of random input to the under-operation 
structure is not available. $\mathrm{RD}$ technique is a special averaging method that has no mathematical basic developed for general cases $[19,20]$. A general review of the application of the RD technique in Operational Modal Analysis (OMA) is presented in this paper.

For the first time, the RD technique was used to calculate a so-called auto-RD function from one output signal [18]. However, it was later extended to multi-output signals. To find RDSs for multi-output signals, it is necessary to select the main signal first; then, the RDSs for the other signals can be consequently found according to the main signal. The RDSs for the main signal and other signals are called auto-RDS and cross-RDS, respectively [1]. It is proved that auto-RDS can significantly decrease noise content; however, cross-RDS incorporates some sort of noises due to its special triggering condition. To overcome this problem, vector triggering RD technique is employed, which can calculate the auto-RDS for all signals simultaneously [21-23].

The application of OMA using RDS was properly addressed in both time and frequency domains by Jorge and Brincker [24]. Later, Ku et al. [10] employed RD technique in time and frequency domains for acceleration data and compared the OMA results.

The infrastructure, such as a bridge, receives various ambient excitations, most of which are non-stationary in nature. Although the RD technique was proved to work well for stationary input excitations, some researchers used it for non-stationary excitations $[19,25,26]$. Lee et al. [25] used the $\mathrm{RD}$ technique to find the free response of the bridge under traffic loadings. He et al. [27] combined the RD technique with empirical mode decomposition and found the modal parameter for a bridge under non-stationary operational excitation. Wu et al. [28] employed the mode separation technique along with the RD technique and determined the modal parameter of cables in a cable bridge.

A complete systematic procedure for designing and implementing SHM using the RD technique on an arbitrary system was well-illustrated by Buff et al. [11]. Using more sensors in RD technique could lead to more accurate results, but it would be more time-consuming as well. Some researchers tried to establish a decentralized RD technique to overcome this problem [19,29].

Damage may be recognized without finding the modal parameters. Gonzalez and Hester [8] identified damage in a bridge-type structure directly from the acceleration data without determining the modal parameters. A scheme showing several damage detection methods using RDS is presented in Figure 1. As shown in Figure 1, RD-based damage localization techniques are generally divided into 2 groups. In the first group, modal parameters should be estimated first; then, damage locations can be found using these modal parameters as damage indexes. However, in the second group, non-modal parameters are employed as damage indicators to locate the possible damage.

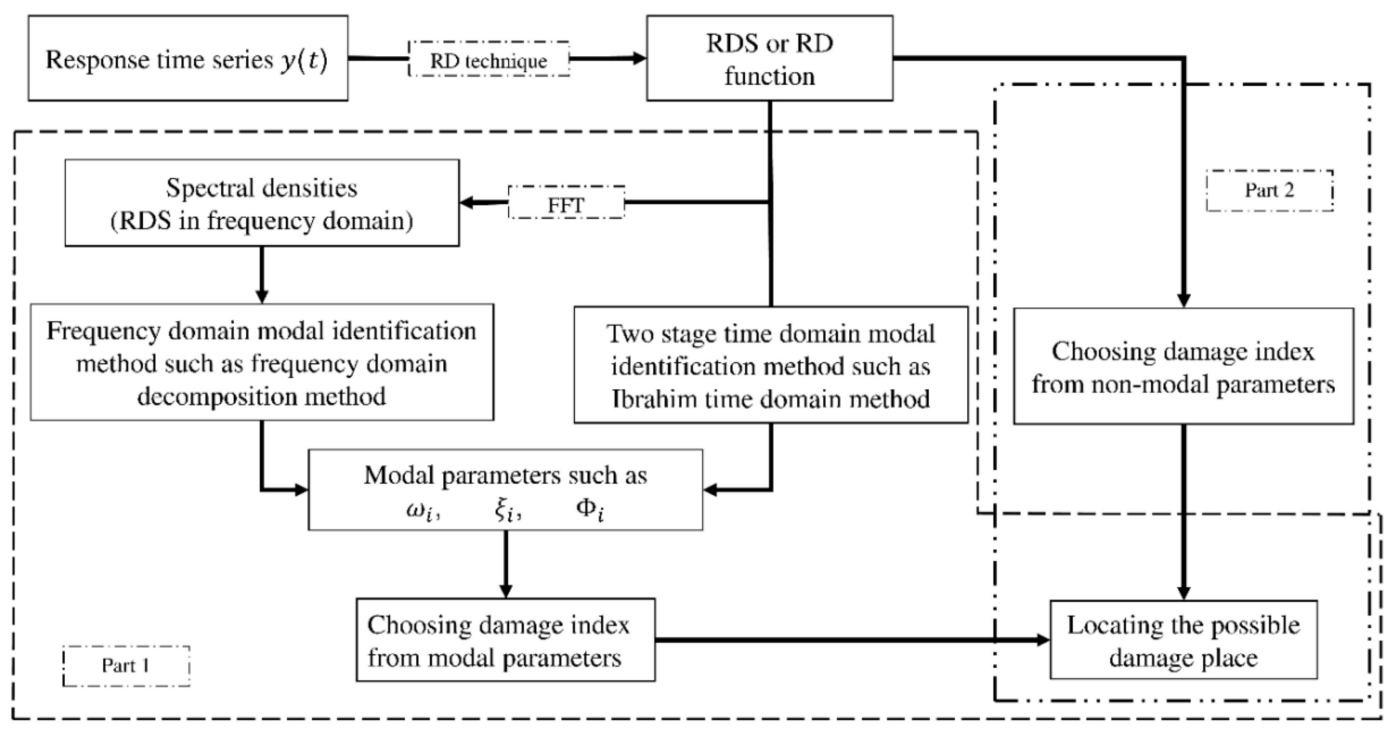

Figure 1. General scheme of damage detection using RD technique. 
The aim of this paper is to find the damage using RDS without calculating the modal parameters. To achieve this goal, acceleration signals were first recorded along the structure, and then the RD technique was used to produce both auto- and cross-RDSs. Each RDS shows a special energy content. Thus, a normalizing factor was defined to drag the RDSs to a unique level of energy. Any possible damage to the bridge disturbs the energy content. This causes the nearest RDS to the damage to show a higher normalized energy than the unique level. Consequently, the damage can easily be detected. To verify the proposed method, two experimental models of a simply supported beam and a scaled arch bridge under moving loads (vehicle simulation) were defined and tested in the laboratory. Then, the acceleration data were recorded along the structure. The results of laboratory models proved that the RDSs can detect the damage location using normalized AI without applying any frequency filtering. This method needs neither knowing the damaged place in advance nor identifying the modal parameters. Additionally, it can properly work in noisy environments.

\section{Basic Theories and Method}

The basic concept of RD technique is very simple, especially if the structural response under random load at each time instant, $t_{i}$, is composed of these two parts:

1. Deterministic response due to initial displacement and velocity and,

2. Random response due to random excitation.

In the mathematical solution provided for RD technique, the input excitation should be stationary, random white noise, Gaussian, and zero-mean [20]. Considering a linear system with multi-degree of freedom, the corresponding equation of motion can be expressed as below:

$$
M \ddot{X}(t)+C \dot{X}(t)+K X(t)=f(t)
$$

in which $M, C$, and $K$ are mass, damping, and stiffness matrices, respectively. Parameter $f(t)$ is a random white noise, zero-mean, stationary, and Gaussian input excitation. $X(t)$ is the displacement recorded in the vertical direction. Assuming that Equation (1) is satisfied at instant $t_{i}$, a simple shift in time $(\tau)$ leads to:

$$
M \ddot{X}\left(t_{i}+\tau\right)+C \dot{X}\left(t_{i}+\tau\right)+K X\left(t_{i}+\tau\right)=f\left(t_{i}+\tau\right),
$$

It is supposed that the input excitation is zero-mean, which can be easily averaged out using the mean of $N(N \rightarrow \infty)$ different starting instants. Computing the mean of $N$ different starting instants can be expressed as below:

$$
\frac{M}{N} \sum_{i=1}^{N} \ddot{X}\left(t_{i}+\tau\right)+\frac{C}{N} \sum_{i=1}^{N} \dot{X}\left(t_{i}+\tau\right)+\frac{K}{N} \sum_{i=1}^{N} X\left(t_{i}+\tau\right)=\frac{1}{N} \sum_{i=1}^{N} f\left(t_{i}+\tau\right)=0,
$$

Defining $Y(\tau)$ as below, Equation (3) turns into a free vibration form as shown in Equation (5).

$$
\begin{gathered}
Y(\tau)=\frac{1}{N} \sum_{i=1}^{N} X\left(t_{i}+\tau\right), \\
M \ddot{Y}(\tau)+C \dot{Y}(\tau)+K Y(\tau)=0,
\end{gathered}
$$

In the literature, $Y(\tau)$ is known as Random Decrement Signature (RDS) $[1,11,23,24,29]$. RD technique is defined as a special averaging method in which $N$ different starting instants, $t_{i}$, are chosen using a so-called triggering level, as shown in Figure 2. Some default values for triggering levels recommended by different researchers are listed in Table 1. 


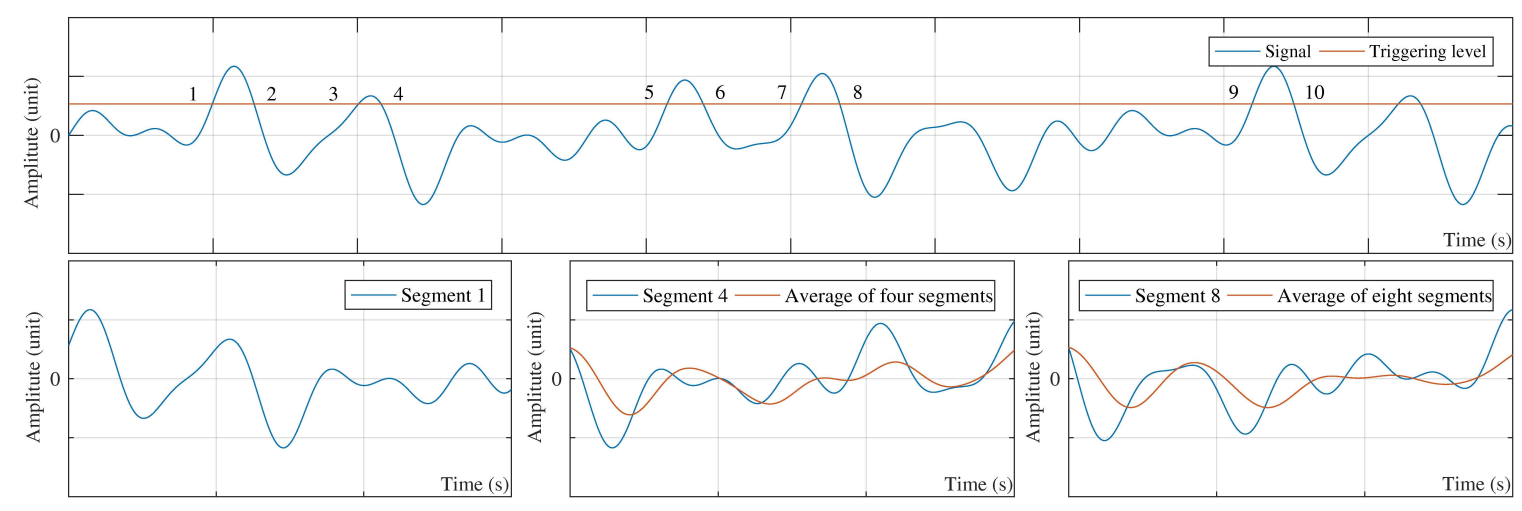

Figure 2. Basic concept of the special averaging in RD technique.

Table 1. Triggering levels recommended by different researchers $[1,22,24]$.

\begin{tabular}{ccc}
\hline Case No. & Description & Relation \\
\hline 1 & Level crossing & $T_{X}\left(t_{i}\right)=\left\{X\left(t_{i}\right)=a\right\}$ \\
2 & Positive points & $T_{X}\left(t_{i}\right)=\left\{a \leq X\left(t_{i}\right)<b\right\}$ \\
3 & Zero crossing with a positive or negative slope & $T_{X}\left(t_{i}\right)=\left\{X\left(t_{i}\right)=0, \begin{array}{l}X>0 \\
\dot{X}<0\end{array}\right.$ \\
4 & Local extremum & $T_{X}\left(t_{i}\right)=\left\{a \leq X\left(t_{i}\right)<b, \dot{X}=0\right\}$ \\
\hline
\end{tabular}

The level-crossing triggering condition was utilized in different studies due to its simplicity. To use the level-crossing triggering condition, the optimum value is assumed as $a=\sqrt{2} \times$ standard deviation [24]. Then, RDS is simply defined as follows:

$$
Y(\tau)=\frac{1}{N} \sum_{i=1}^{N} X\left(t_{i}+\tau\right) \mid X\left(t_{i}\right)=a,
$$

In the Equation (6), two parameters are questionable, namely $N$ and $\tau$. These two parameters can control the consuming time and cost, especially in long-term SHM. The minimum acceptable value for $N$ is 100, while 1000 seems to give a stable result [30]. For parameter $\tau$, the RDS should have enough length to represent a full frequency content of the original response.

The time and cost in RD technique are mainly affected by three parameters, namely, triggering level (a), length of RD signature $(\tau)$, and number of signals. According to Equation (6), triggering level has the greatest effect on the calculation's time and increases the number of segments, especially when the acceleration data are utilized in the analyses. A small change in the parameter $a$ could increase $N$ by hundreds.

All the above illustrations are only for single time-history data. In order to control the safety and health of infrastructures, such as bridges, a set of sensors distributed along the structure are necessary. Calculating the RDS in multi-channel signals was well-illustrated by Ibrahim [1]. He supposed that if the RDS for a signal is called auto-RDS, the cross-RDS could then be computed using triggering information on the auto-RDS. For auto and cross-RDSs, the following equations can be used [1]:

$$
\begin{gathered}
Y_{m m}(\tau)=\frac{1}{N} \sum_{i=1}^{N} X_{m}\left(t_{i}+\tau\right) \mid X_{m}\left(t_{i}\right)=a, \\
Y_{m c}(\tau)=\frac{1}{N} \sum_{i=1}^{N} X_{c}\left(t_{i}+\tau\right) \mid X_{m}\left(t_{i}\right)=a,
\end{gathered}
$$

in which $Y_{m m}(\tau)$ is the auto-RDS calculated from the main signal $\left(X_{m}(t)\right)$ and $Y_{m c}(\tau)$ is the cross-RDS calculated from the signal $X_{c}(t)$ using the triggering information of the main signal. Figure 3 shows the concept of auto and cross-RD signature. As shown in Figure 3, the segments of cross-RDS will be 
chosen based on the instant times in which triggering level crosses the main signal. Thus, it is seen that the initial condition of cross-RDS is not equal to the triggering level $a$.

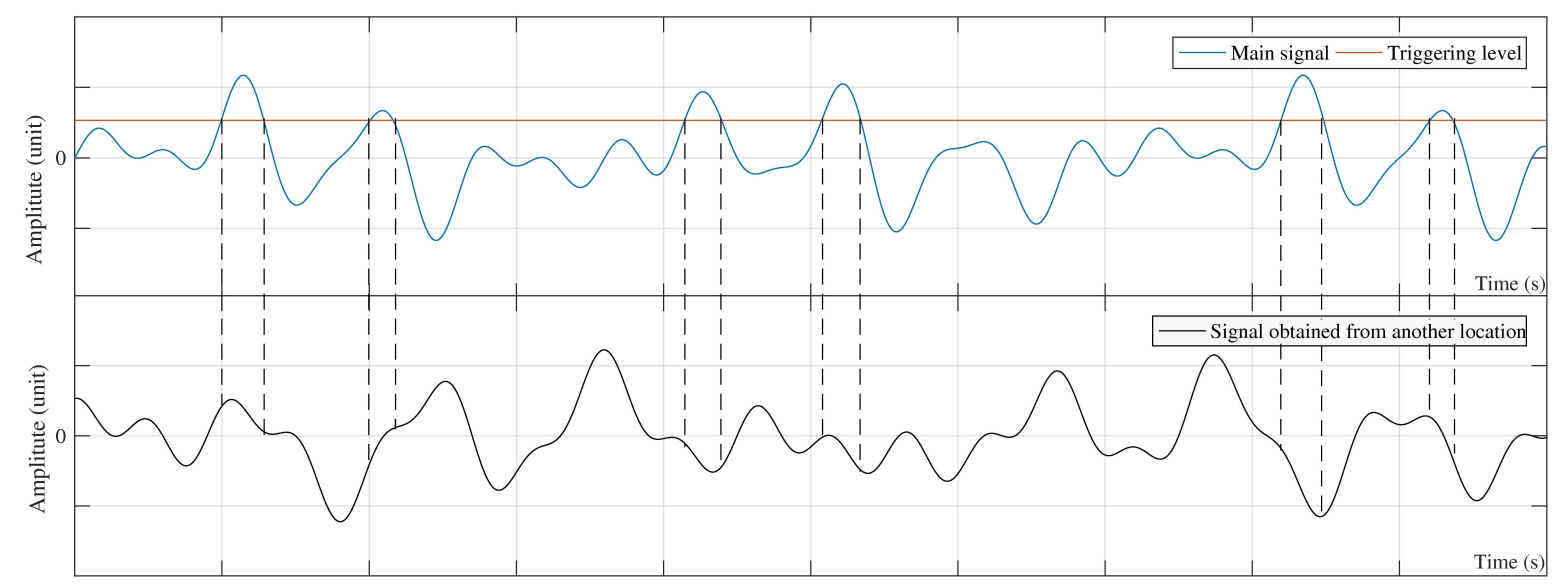

Figure 3. The concept of calculating the cross-RD function.

The triggering level in the main signal causes the auto-RDS to have an initial value equal to $a$. However, this initial condition cannot occur for cross-RDS. Here, the initial value of cross-RDS is equal to the average of the $N$ different starting instants of the signal $X_{\mathcal{c}}(t)$. Therefore, due to this special averaging procedure, the auto-RDS contains less noise than the cross-RDS [24].

As mentioned above, a mathematical solution for RD technique is only available for the zero-mean, stationary, Gaussian, and random white noise input excitations. However, most of the ambient and random excitations are non-stationary in nature, such as traffic on the bridges. A large body of research available on the literature employed RD technique to find the modal parameters and damages for non-stationary excitations $[19,25,27,28]$.

\section{Laboratory Models of Simply Supported Beam and Arch Cable Bridge}

\subsection{Experimental Study of the Simply Supported Beam}

The accuracy of the proposed method was verified using two laboratory models, namely, a simply supported beam and an arch cable bridge. This part illustrates the simply supported beam model constructed in the laboratory of civil and structural health monitoring, Zhejiang University, Hangzhou, China. The laboratory model consists of a 6-m long I-shaped beam. In the cross-section, the beam's flanges measure $0.072 \mathrm{~m} \times 0.005 \mathrm{~m}$, while the web measures $0.112 \mathrm{~m} \times 0.005 \mathrm{~m}$. The beam is made of structural steel with Young's modulus of $200 \mathrm{GPa}$, a Poisson ratio of 0.3 , and a density of $7850 \mathrm{~kg} / \mathrm{m}^{3}$. In this model, a bogie was used to simulate the moving load. When the bogie passes through the beam, the acceleration data were recorded at 9 stations with a fixed distance of $0.6 \mathrm{~m}$ simultaneously [18]. Figure 4 shows the positions of accelerometers attached to the simply supported beam in the laboratory. The beams, bogie, and few of the accelerometers are shown in Figure 5. A typical crack, manually created on the beam, and its dimensions are shown in Figure 6. In this figure, the delta represents the ratio of the height of crack to the height of the beam.

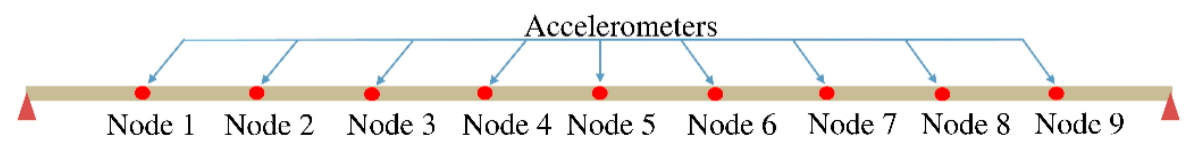

Figure 4. Locations of accelerometers to record acceleration data. 


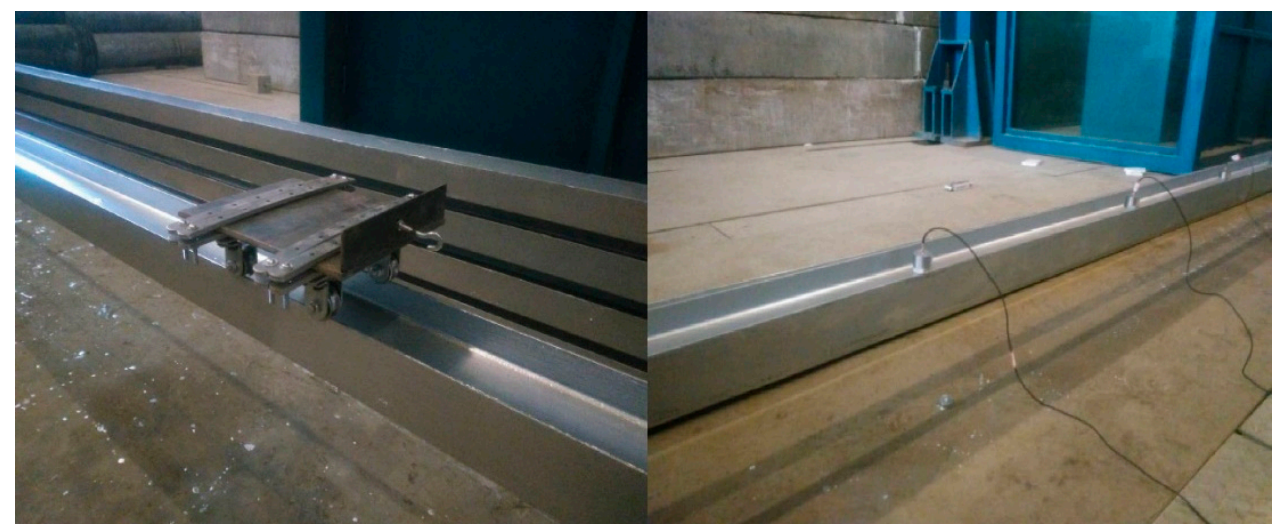

Figure 5. A general view of the vehicle and accelerometers.

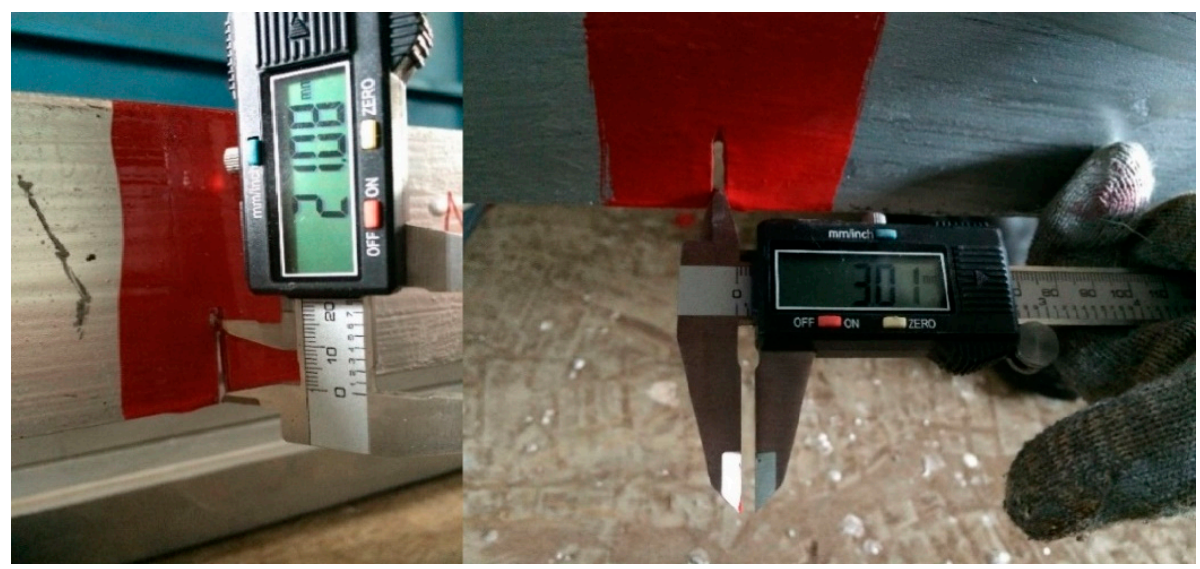

Figure 6. A general view of the crack. The right photo shows the width of the crack (around $0.003 \mathrm{~m}$ ), and the left photo shows the height of the crack for delta $=30 \%(0.072 \times 0.3=0.0216 \mathrm{~m} \approx 0.021)$.

The accelerometers were attached to the bottom of the beam. Due to use of the flanges as a lane for bogie, the bogie could simply run over the beam. Different velocities $(0.3,0.4$, and $0.5 \mathrm{~m} / \mathrm{s})$ were considered to examine the effect of velocity variation on damage detection accuracy. The acceleration data were recorded with a sampling frequency of $500 \mathrm{~Hz}$ in this model. Table 2 shows damage scenarios considered in the simply supported beam model.

Table 2. Two damage scenarios considered in the laboratory model of the simply supported beam.

\begin{tabular}{ccc}
\hline Scenario & $\mathbf{1}$ & $\mathbf{2}$ \\
\hline Crack depth to beam flange ratio & $40 \%$ & $30 \%$ \\
Location & at node 5 (mid-span) & at node 7 \\
Name & N5D40 & N7D30 \\
\hline
\end{tabular}

Note: The scenarios are designated as N (damage location) D (delta). For example, N5D40 refers to a scenario where delta $=40 \%$ at node 5 .

\subsection{Experimental Study of the Arch Cable Bridge}

A scaled arch bridge model was designed and assembled in the department of civil engineering, Zhejiang University, China [31]. The model is a half-through steel-tube arch bridge with a main span of $6 \mathrm{~m}$ and 14 cables in total. This arch cable bridge is shown in Figure 7. The material properties of the bridge, including Young's modulus, density, and Poisson's ratio are assumed as $2.06 \times 10^{6} \mathrm{~N} / \mathrm{mm}^{2}$, $7.698 \times 10^{-5} \mathrm{~N} / \mathrm{mm}^{3}$, and 0.3 , respectively. 


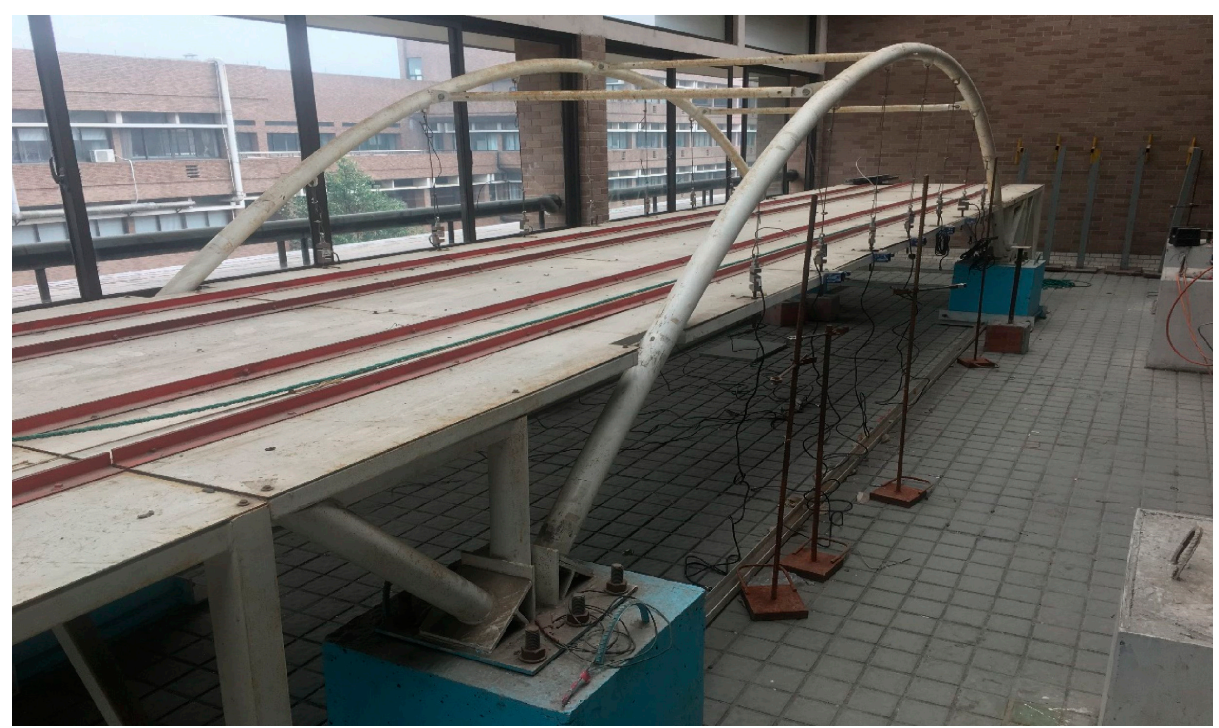

Figure 7. The arch cable bridge lab model built at Zhejiang University Laboratory.

Figure 8 shows the location of accelerometers attached close to the cables on one side of the bridge. Each cable is composed of 7 twisted sub-cables. Figure 9 shows the twisted cable. The damage is applied to the model by cutting the small twisted cables. It enables us to simulate $14 \%$ to $100 \%$ damage in each cable. Cutting one of the twisted cables corresponds to $14 \%$ damage $\left(\frac{1}{7} \cong 0.14 \%\right)$, while removing the whole twisted cables equals $100 \%$ damage.

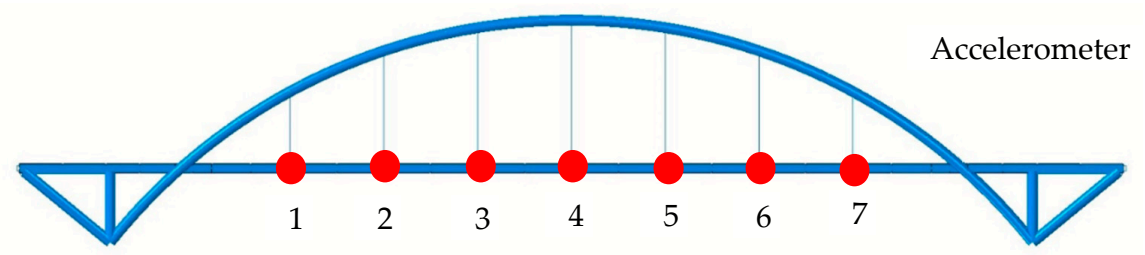

(a) Schematic view of the bridge with positions of accelerometers marked by red circles.

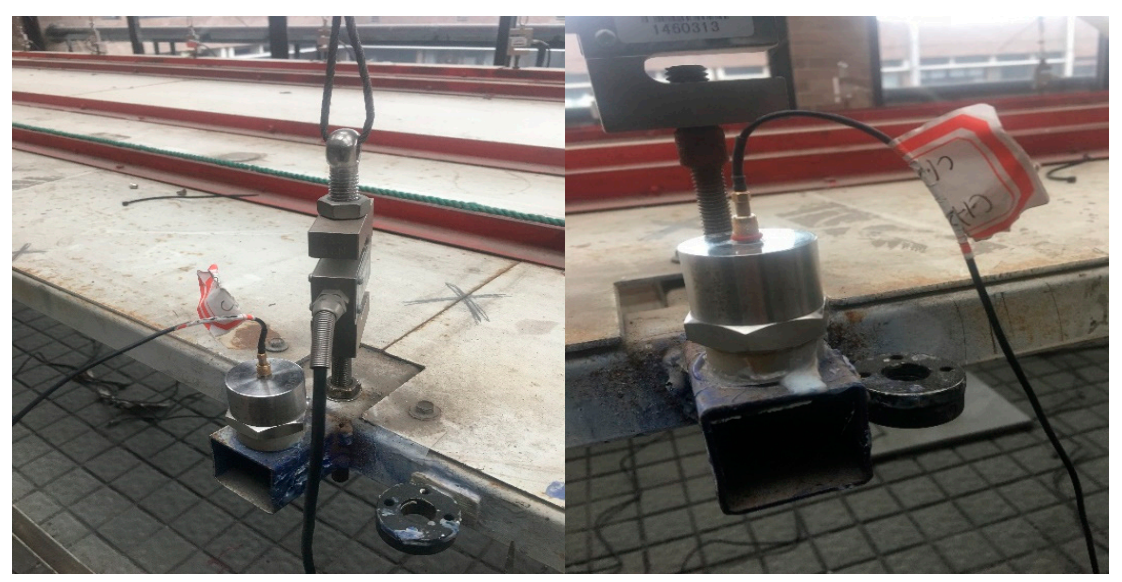

(b) Accelerometer attached close to cable.

Figure 8. Side view of the model showing (a) locations of accelerometers installed on one side of the bridge and (b) accelerometers attached close to the cables. 


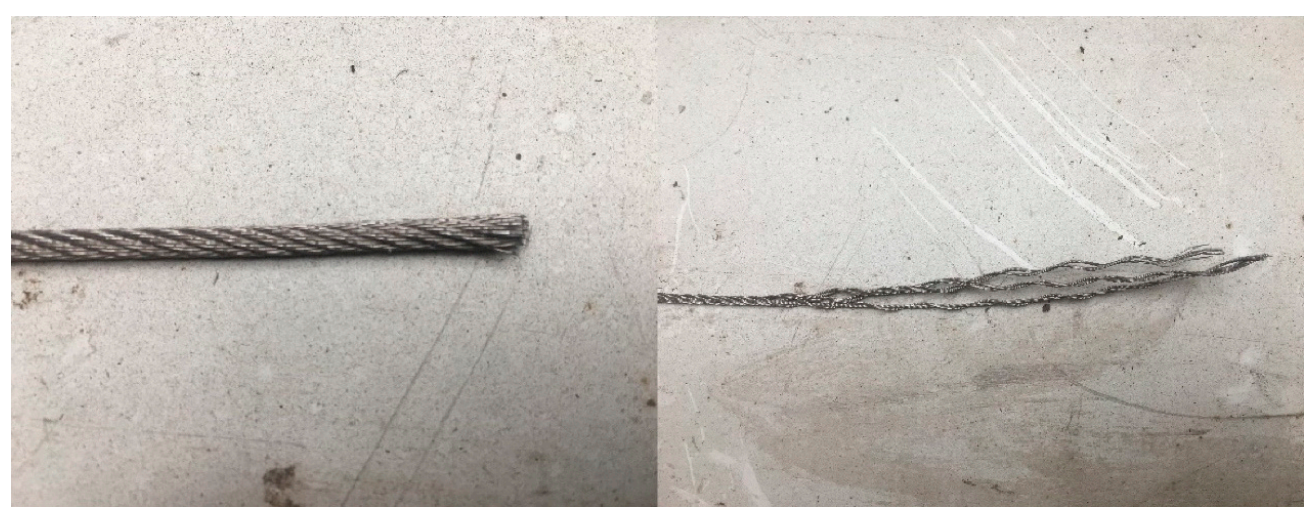

Figure 9. The twisted cable composed of 7 small sub-cables.

Five different damage scenarios were considered in the laboratory model of arch cable bridge, as listed in Table 3.

Table 3. Five damage scenarios considered in a laboratory model of the bridge.

\begin{tabular}{ccc}
\hline Scenario & $\mathbf{1}$ & $\mathbf{2}$ \\
\hline section area loss in twisted cable & $43 \%, 70 \%$, and $100 \%$ & $43 \%$ and $70 \%$ \\
Location & Node 2 & Node 4 \\
Name & Second node from left side & (middle of bridge) \\
\hline
\end{tabular}

Note: To simplify the naming process of different scenarios, each condition was named as $\mathrm{N}$ (place of damage) $\mathrm{D}$ (number of small cables removed from the twisted cable). For example, N4D1-7 means 14\% damage at node 4 $(1 / 7 \cong 14 \%)$. The no-damage condition is shown by WD (without damage).

\section{Results and Discussion}

\subsection{Preliminary Data of Simply Supported Beam}

The beam was loaded using a $27.5 \mathrm{~kg}$ bogie at different speeds $(0.3,0.4$, and $0.5 \mathrm{~m} / \mathrm{s})$ to simulate the traffic moving load. All acceleration data were recorded at a sampling frequency of $500 \mathrm{~Hz}$. The node 1 (according to Figure 4) was considered as the location of the main signal. Auto-RDS for node 1 and cross-RDSs for Nodes 2-9 were calculated using level-crossing triggering condition. As mentioned previously, to use the level-crossing triggering condition, the optimum value was assumed to be $\mathrm{a}=\sqrt{2} \times$ standard deviation [24]. In this work, this optimum value was computed for all signals, and the minimum of these values was chosen as triggering condition of the main signal. This step was made by more than 2000 segments $(N>1000)$ for each RDS. Figure 10 shows three signals of the intact beam, namely, the acceleration signal recorded in node 1, the auto-RDS of node 1, and the cross-RDS of node 5 (middle of the beam). The length of RDS in the whole of this work is $5 \mathrm{~s}$. 


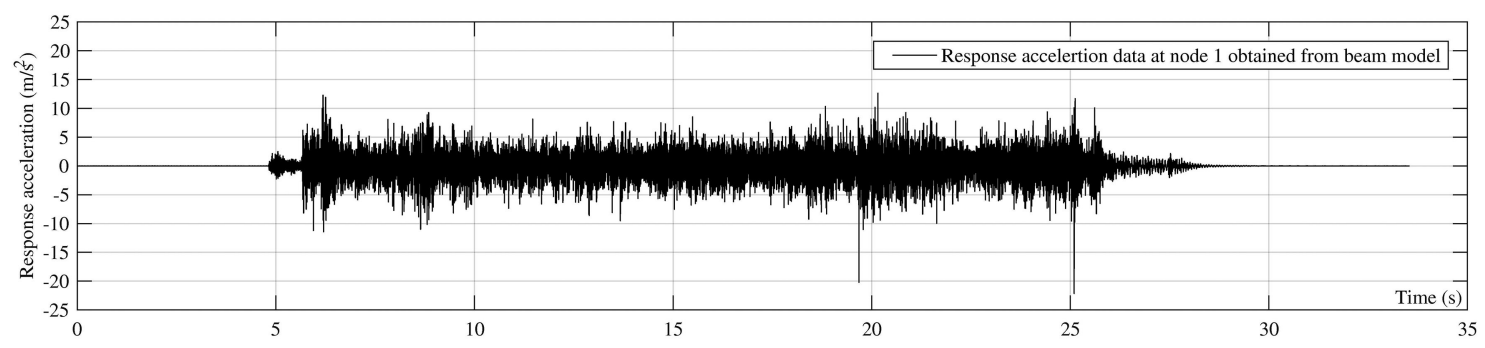

(a) Response acceleration data at node 1 under moving load, speed $=0.3 \mathrm{~m} / \mathrm{s}^{2}$

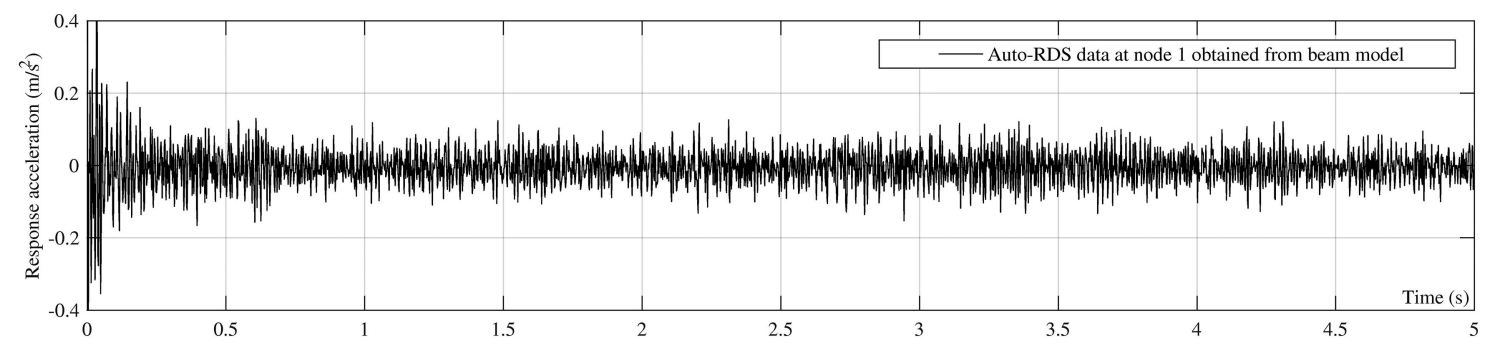

(b) Auto-RDS data at node 1 under moving load, speed $0.3 \mathrm{~m} / \mathrm{s}^{2}$

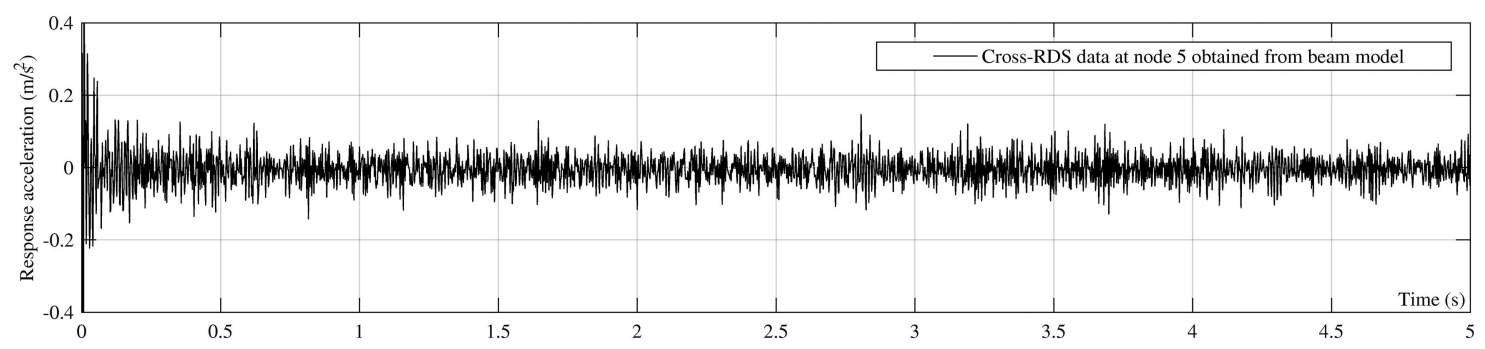

(c) Cross-RDS data at node 5 under moving load, speed $0.3 \mathrm{~m} / \mathrm{s}^{2}$

Figure 10. (a) Response acceleration data recorded at node 1; (b) auto-RDS of node 1; and (c) cross-RDS of node 5 .

\subsection{Preliminary Data of Arch Cable Bridge}

The bridge was loaded by a truck at different weights and speeds $(90,110$, and $130 \mathrm{~kg}$, and 0.3 , 0.4 , and $0.5 \mathrm{~m} / \mathrm{s}$ ) to simulate the traffic moving load. The acceleration signal in the mid-span of the arch cable bridge is shown in Figure 11a. All the seven accelerometers simultaneously record the acceleration signal with a sampling rate of $1000 \mathrm{~Hz}$. Figure $11 \mathrm{~b}, \mathrm{c}$ represents the auto-RDS of node 1 and cross-RDS of node 4 (middle of the bridge) calculated from the signal shown in Figure 11a, respectively. 


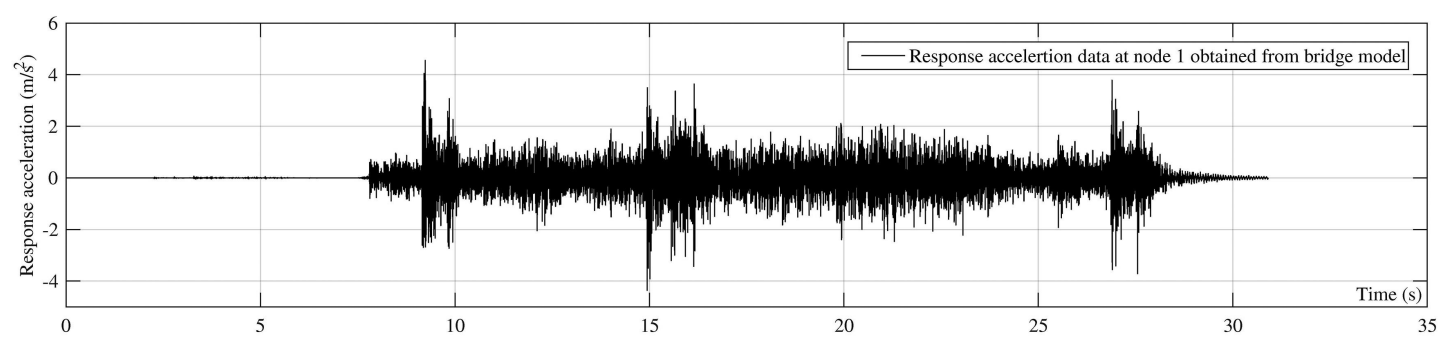

(a) Response acceleration data at node 1 under moving load, speed $=0.3 \mathrm{~m} / \mathrm{s}^{2}$

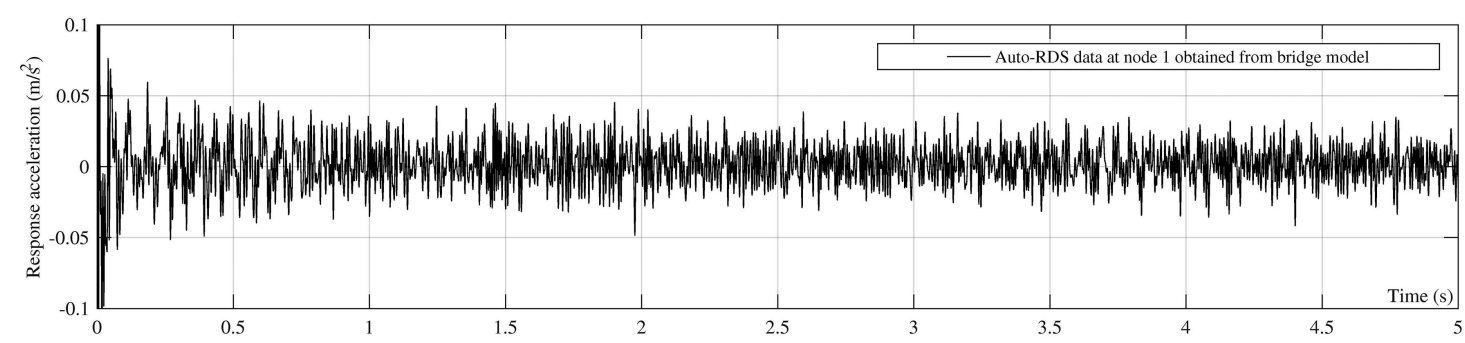

(b) Auto-RDS data at node 1 under moving load, speed $=0.3 \mathrm{~m} / \mathrm{s}^{2}$

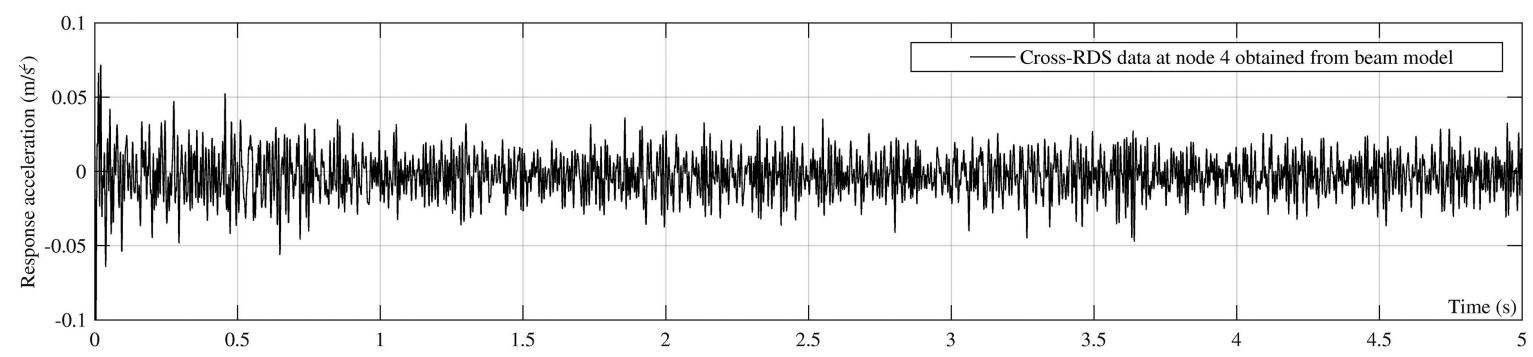

(c) Cross-RDS data at node 4 under moving load, speed $=0.3 \mathrm{~m} / \mathrm{s}^{2}$

Figure 11. (a) Response acceleration data recorded at node 1, (b) auto-RDS of node 1, and (c) cross-RDS of node 5 .

\subsection{Normalizing the Arias Intensity along the Structure}

As previously pointed out and shown in Figure 1, most of the damage detection methods are based on estimating modal parameters through RDSs. These parameters are then used as damage indicators to identify the damage locations. However, recent research carried out stipulates how to find damage without detecting the modal parameters $[8,13]$. Taking this approach, Arias Intensity (AI) is employed as a new damage indicator in this paper to locate the damage without calculating any modal parameter. AI is one of the most famous energy criteria defined by Arturo Arias in 1970 [32]. The Arias intensity calculates the energy of the acceleration signal expressed as below:

$$
I_{A}\left(\frac{m}{s}\right)=\frac{\pi}{2 g} \int_{0}^{T} a^{2}(t) d t
$$

in which $I_{A}, T$, and $a(t)$ are $\mathrm{AI}$, duration of acceleration, and acceleration data, respectively. Using this definition, $\mathrm{AI}$ is calculated as a scalar and invariant value. Additionally, it contains the full range of frequencies and time duration of the signal.

To begin with the proposed method, Equation (9) was applied to all the recorded signals, and their corresponding AI values were determined. For instance, Figure 12 shows the results for each sensor from both auto and cross-RDSs of intact structure individually. 


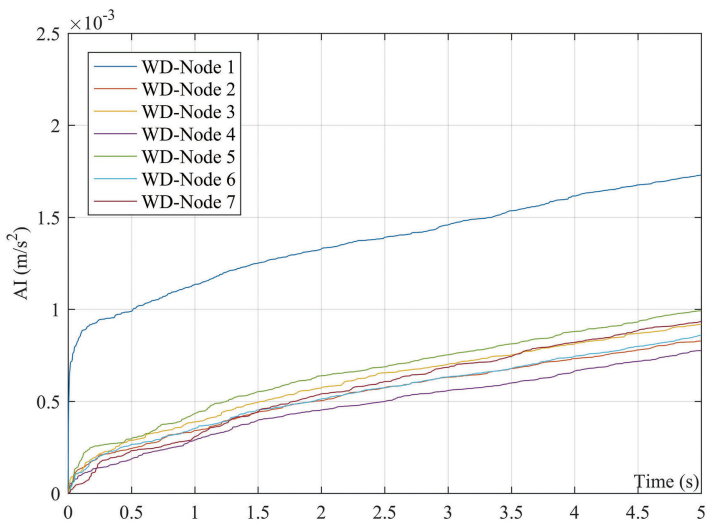

(a)

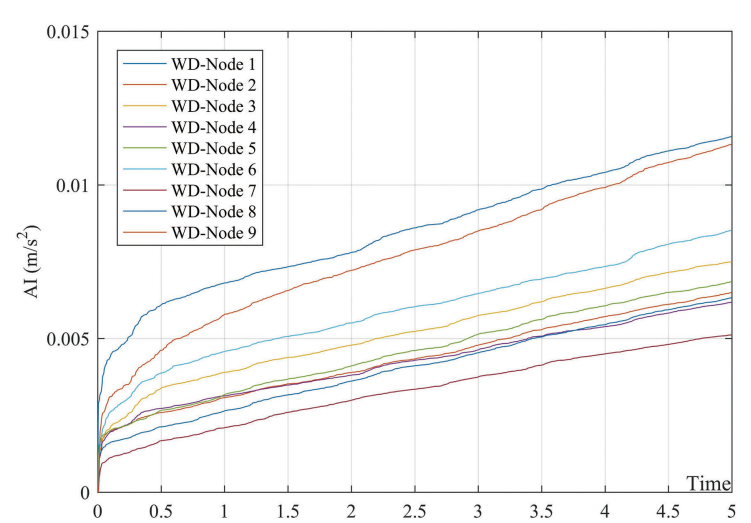

(b)

Figure 12. The AIs calculated from the RDSs for each sensor of the intact structure individually, considering the speed as $\mathrm{v}=0.3 \mathrm{~m} / \mathrm{s}$. (a) Al calculated for intact bridge and (b) AI calculated for the intact beam.

It is supposed that the damage location can be estimated from the absolute difference value of the AIs calculated from a structure in damage and non-damage conditions. However, as shown in Figure 12, the AI differs from node to node. Thus, it is impossible to find any damage without normalization. To normalize the AI spectrums, the following equations are used:

$$
\begin{aligned}
I_{A-\text { normalized }} & =\frac{\pi}{2 g} \int_{0}^{T}(\beta a(t))^{2} d t, \\
\beta & =\sqrt{\frac{1000}{I_{A}}},
\end{aligned}
$$

Equation (10) causes the AIs to normalize to 1000. The parameter $\beta$ is normalization factor and should be calculated only for structures without damage. Figure 13 and Table 4 show the normalized AIs and corresponding $\beta$ s.

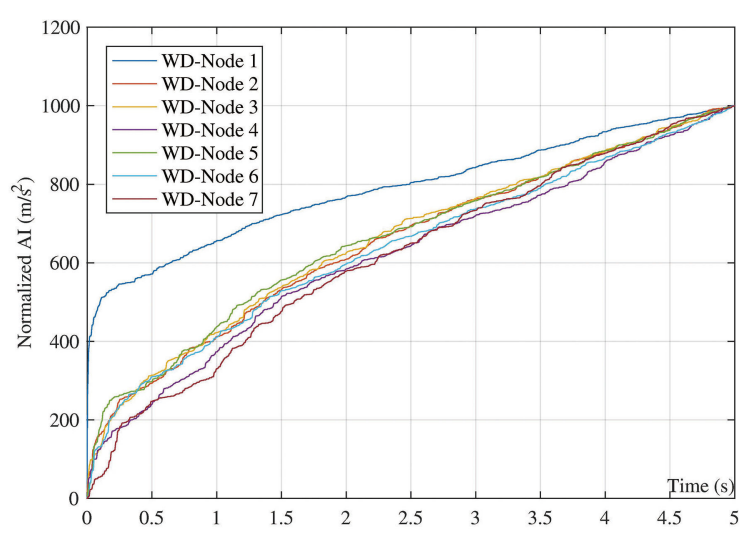

(a)

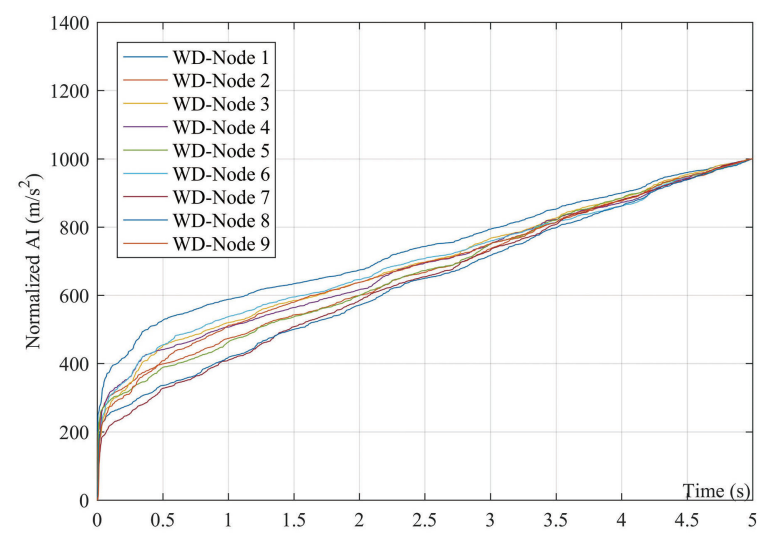

(b)

Figure 13. The AIs after normalization for the structure under moving load considering the speed as $\mathrm{v}=0.3 \mathrm{~m} / \mathrm{s}$. (a) Normalized Al calculated for intact bridge and (b) normalized AI calculated for the intact beam. 
Table 4. $\beta$ calculated for all signals under moving load in the laboratory for no-damage condition considering the speed as $\mathrm{v}=0.3 \mathrm{~m} / \mathrm{s}$.

\begin{tabular}{cccccccccc}
\hline Parameter & Node $\mathbf{1}$ & Node $\mathbf{2}$ & Node $\mathbf{3}$ & Node $\mathbf{4}$ & Node $\mathbf{5}$ & Node $\mathbf{6}$ & Node $\mathbf{7}$ & Node 8 & Node 9 \\
\hline$\beta$ (for bridge) & 1049 & 1306 & 1256 & 1427 & 1252 & 1354 & 1381 & - & - \\
$\beta$ (for beam) & 294 & 392 & 365 & 402 & 382 & 342 & 442 & 397 & 297 \\
\hline
\end{tabular}

Although Table 4 shows the value of $\beta$ considered to normalize the AI of RDSs, it is limited to the speed of $0.3 \mathrm{~m} / \mathrm{s}$. Considering different weights and velocities leads to a different $\beta$. Twenty-nine laboratory tests were assumed for the non-damage models, in which twenty-one tests were implemented on the bridge with 3 different weights $(90,110$, and $130 \mathrm{~kg})$ and velocities $(0.3,0.4$, and $0.5 \mathrm{~m} / \mathrm{s}$ ). The remaining 8 tests were implemented on the beam considering a $27.5 \mathrm{~kg}$ weight and three different velocities $(0.3,0.4$, and $0.5 \mathrm{~m} / \mathrm{s})$. In each test, the parameter $\beta$ was calculated for all the nodes. Figure 14 shows the $\beta$ for node 1 of both bridge and beam under moving load at different weights and velocities.

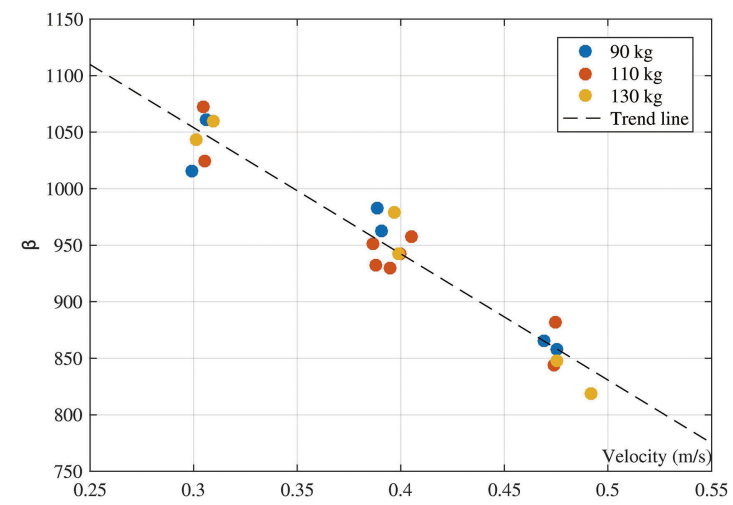

(a)

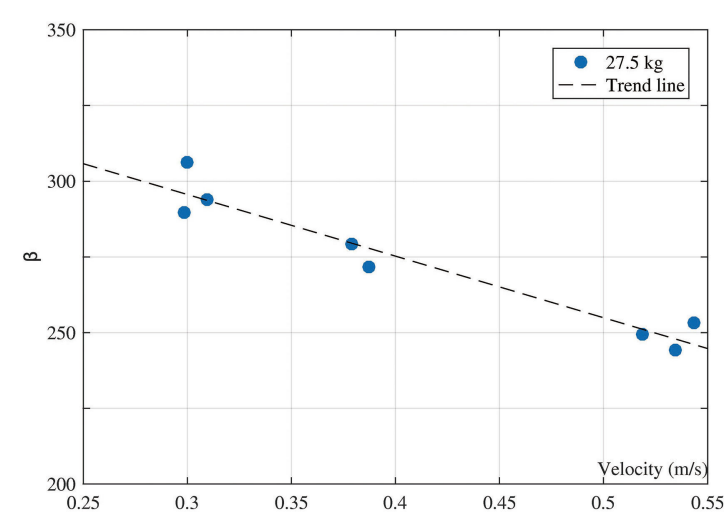

(b)

Figure 14. Normalizing factor for the structure under moving load at (a) node 1 of the intact bridge and (b) node 1 of the intact beam.

Two points can be deduced from Figure 14. First, in our models, $\beta$ follows a linear pattern and has an inverse relationship with velocity. Secondly, $\beta$ has no relationship with changes in the weights. For instance, there is no relationship between different weights at speed $v=0.4 \mathrm{~m} / \mathrm{s}$. Using the linear relationship between $\beta$ and velocity may lead to a new $\beta$ for other velocities. This linear relationship can be defined as follows:

$$
\beta=x \vartheta+y,
$$

in which $\vartheta$ is the speed of moving load. The two coefficients $x$ and $y$ can be estimated for each node. Figure 14 shows how to use a trend line to estimate $x$ and $y$ for node 1 . The results are reported in Table 5 showing $x$ and $y$ for all the nodes of the beam and bridge.

Table 5. The coefficients $x$ and $y$ calculated for all nodes of the beam and bridge for the no-damage condition.

\begin{tabular}{ccccccccccc}
\hline Parameter & Node $\mathbf{1}$ & Node $\mathbf{2}$ & Node 3 & Node 4 & Node 5 & Node 6 & Node 7 & Node 8 & Node 9 \\
\hline \multirow{2}{*}{ Beam } & $x$ & -203 & -498 & -241 & -377 & -348 & -228 & -457 & -444 & -238 \\
& $y$ & 356 & 535 & 441 & 514 & 475 & 432 & 567 & 525 & 378 \\
\hline \multirow{2}{*}{ Bridge } & $x$ & -1116 & -1954 & -1687 & -2249 & -1689 & -1874 & -1949 & - & - \\
& $y$ & 1389 & 1901 & 1769 & 2112 & 1766 & 1925 & 1975 & - & - \\
\hline
\end{tabular}


Equation (12) and Table 5 provide a baseline for these laboratory models and normalize the AI at different velocities.

\subsection{Locating the Connection Loss in the Cables for the Arch Cable Bridge}

When damage occurs, the cable experiences a localized loss of stiffness. This stiffness reduction will change the distribution of energy in the structure. Consequently, $\beta$ cannot normalize the AIs calculated from all the signals to 1000. It is assumed that the stiffness reduction in the cable amplifies the acceleration signal on damage location more than other places along the bridge. Therefore, the higher amplitude leads to an AI greater than 1000 after normalization.

Figure 15 shows the normalized AI for N2D7-7, in which cable in node 2 receives full damage by losing the connection. It is clear that, except node 2 , which is slightly higher than 1000 , all other nodes show a result less than 1000 . Since all the AIs were previously normalized to 1000 in the bridge without damage, it is possible to deduct 1000 from all the AIs and find the damage according to positive amounts. Figure 15 is re-plotted as a bar chart (Figure 16a). Figure 16b shows the normalized AI along the bridge after subtracting 1000 for the case N2D7-7 (for simplicity, negative values are considered zero).

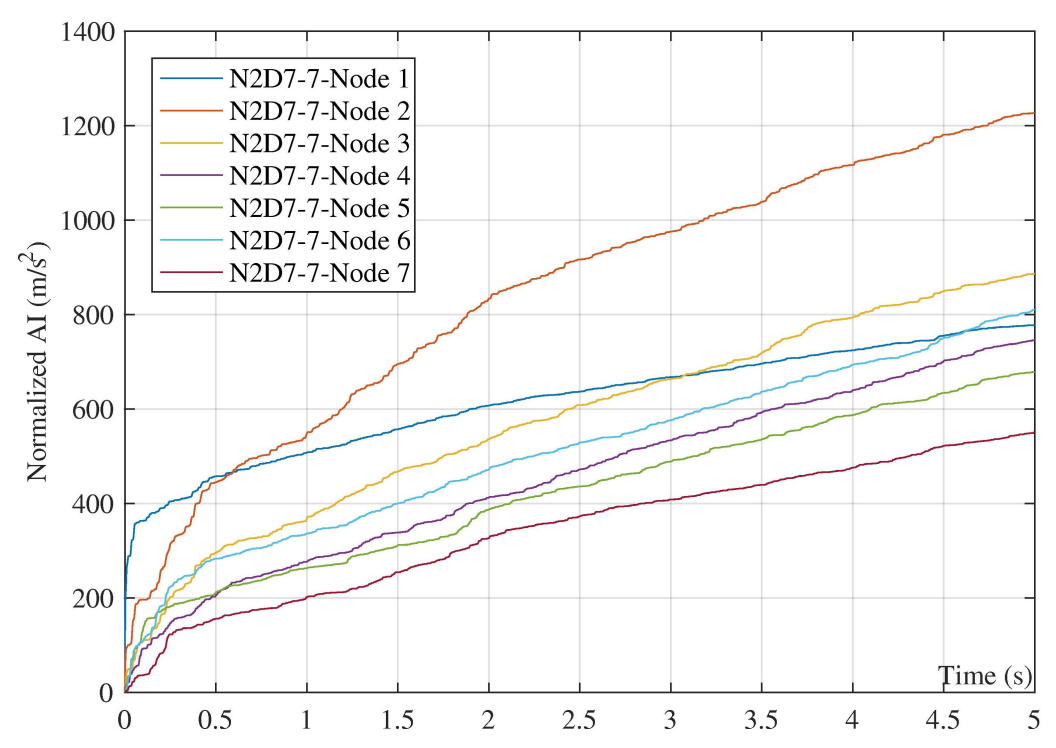

Figure 15. Normalized AI for 100\% damage in cable 2 under moving load.

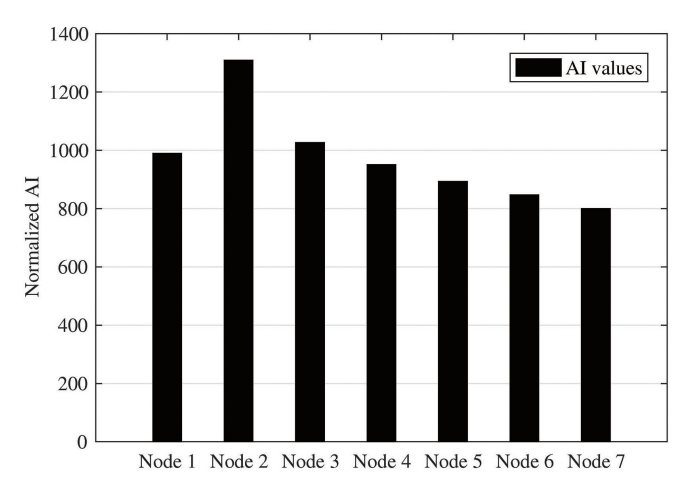

(a)

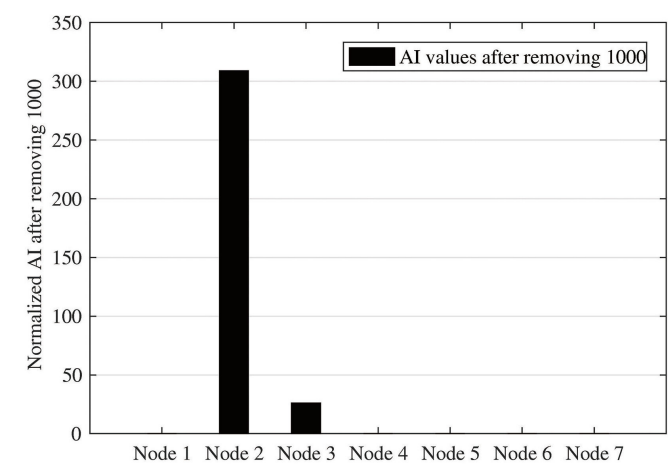

(b)

Figure 16. Distribution of normalized AI along the bridge (a) for the node N2D7-7 and (b) after subtracting 1000 from the N2D7-7 result. 


\subsection{Detecting Small Damage Ratios in Laboratory Models}

So far, it is explained how $100 \%$ damage to a cable, such as losing the connection between a cable and the bridge, could be located in the RDSs using AI as damage indicator. There are, however, some conditions in which a cable partially loses its stiffness due to some reasons such as corrosion. As shown in Figure 9, each cable is composed of 7 twisted thin cables. Therefore, it is possible to model the damage from $14 \%$ to $100 \%$ in one cable. In this section, the detection of small damage is addressed and the capability of the proposed method is assessed through laboratory results.

A case with $100 \%$ damage in the beam is equivalent to a cut through the whole beam, which does not seem rational. Hence, the 100-percent damage scenario is not described. Instead, other damage ratios are targeted as shown in Figure 6 and illustrated in Table 2.

Figure 17 shows the $\mathrm{AI}$ in the damage location, while the other values are zero along the beam. It should be noticed that the aim of the proposed method is to find the maximum normalized AI along the beam. Due to normalizing the AIs, subtracting 1000 from AIs could yield much better results (Figure 16b). In the beam, subtraction of 1000 from the AIs leads to positive values only in the nodes close to damage location.

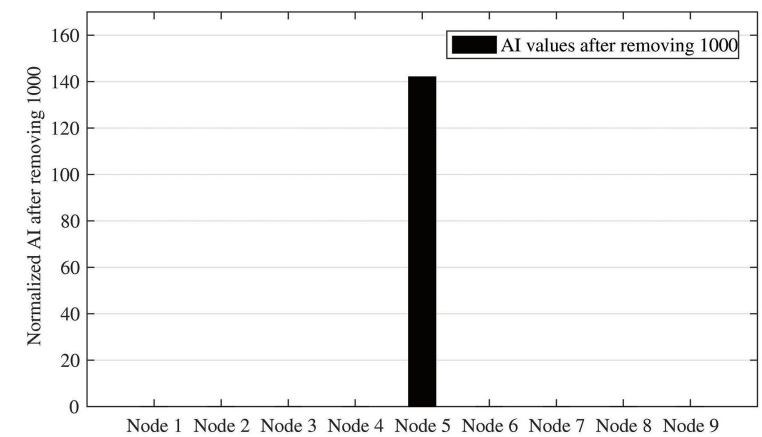

(a)

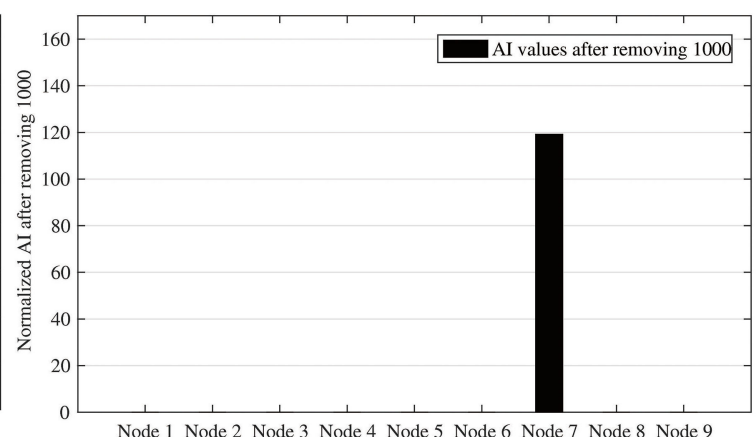

(b)

Figure 17. Distribution of AIs along the beams for all accelerometers assuming (a) Case N5D40 from beam model: delta $=40$ at Node 5 and (b) Case N7D30 from beam model: delta $=30$ at Node 7 .

Figure 18 shows how small damage can be found in a cable using RDSs and normalized AI. In this figure, the damage occurs in node 2 (second cable from left) and node 4 (middle of the bridge) with different damage ratios. As observed in all these scenarios, the maximum amount of normalized AI appears close to damage location.

According to Figure 18, it is proved that the proposed method can locate the damage accurately. The small positive amount of normalized AI in other places (nodes 1,3, and 7) shows that the damage can affect those nodes as well. The fact that the proposed method can provide acceptable results in a noisy environment is illustrated in Figures 17 and 18. This result is relevant for velocities between 0.3 and $0.5 \mathrm{~m} / \mathrm{s}$. Using the proposed model in a noisy environment at a speed more than $0.5 \mathrm{~m} / \mathrm{s}$ is accompanied by a margin of error.

It should be mentioned that the proposed model could be used as a real-time damage detection method if the optimized values of truck velocity, triggering level, number and location of accelerometers, and length of signal are calculated in advance. 


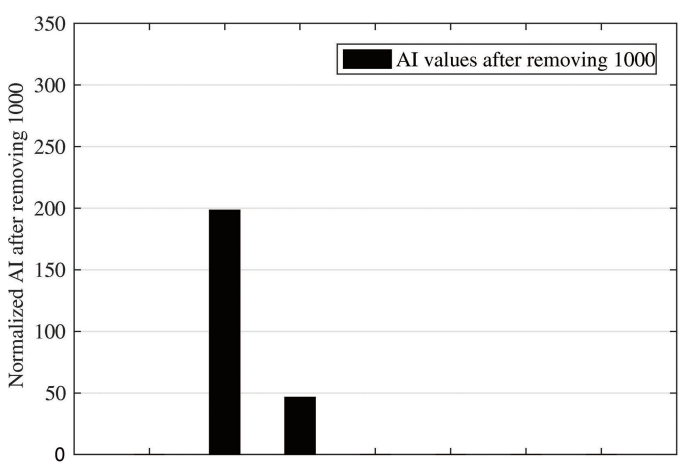

(a)

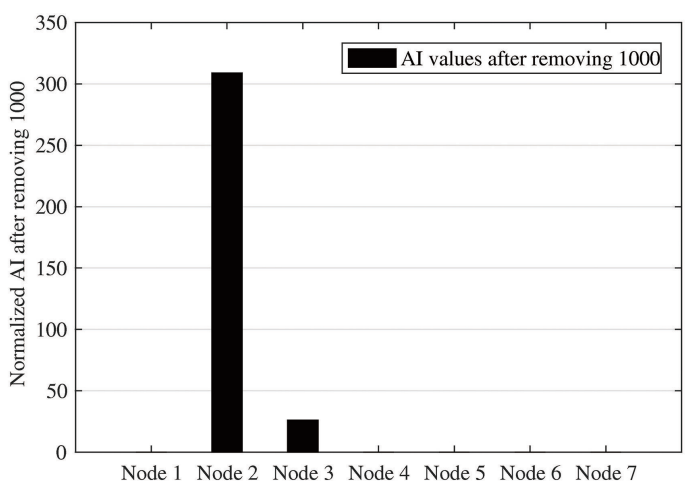

(c)

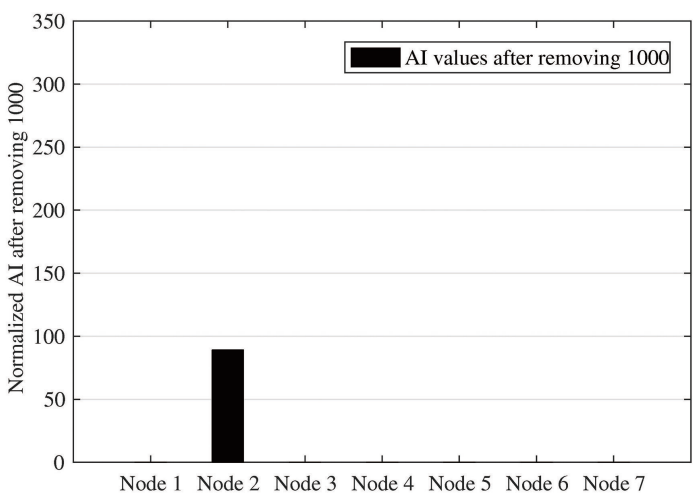

(e)

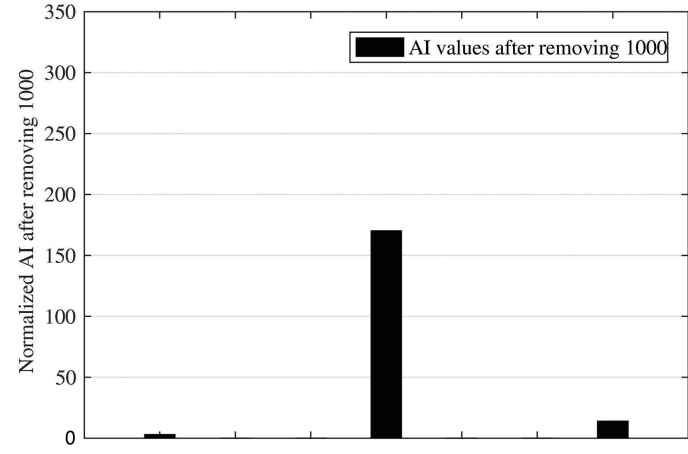

(b)

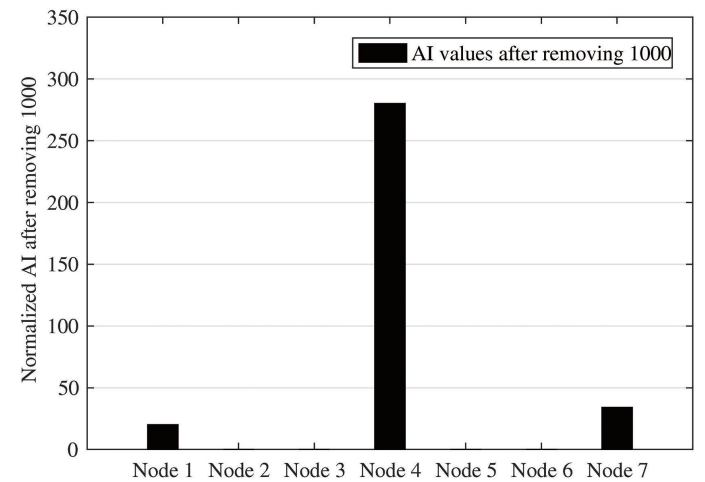

(d)

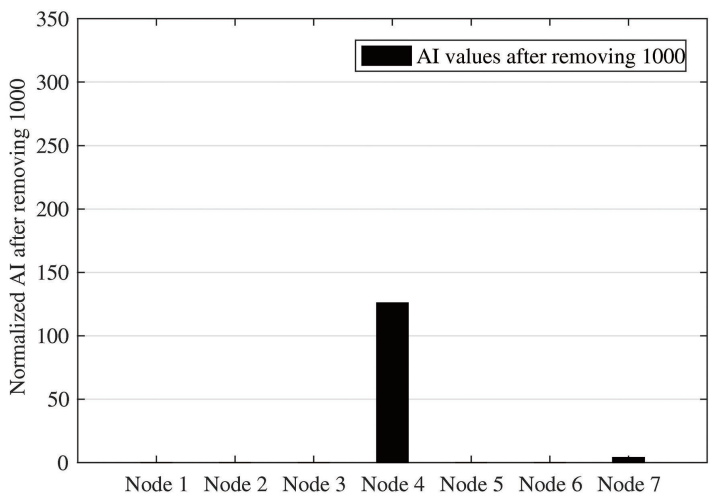

(f)

Figure 18. Normalized AI for six different damage scenarios obtained from laboratory models. $(\mathbf{a}, \mathbf{c}, \mathbf{e})$ Cases N2D7-7, N2D5-7, and N2D3-7 of laboratory model; (b,d,f) cases N4D7-7, N4D5-7, and N4D3-7 of a laboratory model.

\subsection{Noise Effect}

The uncertainty imposed by the noise has not been discussed in this paper. However, it can be claimed that the results may not be highly affected by the incorporated noise. To further argue this claim, a closer look at the proposed method is addressed here. Based on the frequency content, two different cases can be assumed: (1) noise and structural response have the same frequency and (2) noise and structural response do not contain similar frequency content. In the first case, since the noise removal can distort the main response, it is not possible to attenuate the noise. However, in the second case, the incorporated noise can be efficiently reduced by using frequency filtering methods. The RD 
technique can act as a de-noising technique. It means that the proposed method essentially attenuates the second category of noise. However, to deal with the first category of noise, the loading parameters such as velocity can be changed so as to get a structural response with frequency content far away from noise frequency contents. If it is not possible, the accuracy of proposed method would then be significantly affected.

One way to detect the incorporated noise in laboratory tests is to separately record the acceleration data without loading. In this research, all the signals begin with a pre-loading segment that lasts for few seconds. This issue can be seen in Figures 10 and 11 of the paper, in which the main loading approximately starts after $5 \mathrm{~s}$. Considering the frequency content of these pre-loading segments, it is found that the similarity between the frequency contents of noise and structural response is small enough to be ignored. It means that the majority of noises belong to the second category and thus could be removed by RD technique.

\section{Conclusions}

This paper proposed an output-only method in which the random decrement technique was employed to produce auto- and cross-RDSs under moving load. Then, AI was calculated to find the energy content of each individual RDS. These AIs were normalized, and a parameter $\beta$ was defined as a normalization factor, thereby highlighting the maximum normalized AI along the structure, which could show the vicinity of damage location accurately. Since the proposed method could calculate the $\beta$ for an intact structure using a linear pattern, there was no need to calculate the response of the non-damage structure.

The main results of the research can be summarized as follows:

1. It was proved that the damage location could be detected using acceleration data, recorded along a structure.

2. Investigating the effect of load-moving velocity, it was shown that the normalizing factor had an inverse linear relationship with velocity.

3. The accuracy of the proposed method was examined through two models, namely a simply supported beam and an arch cable bridge.

4. It was indicated that the proposed method could easily find the location of a single damage on a noisy signal.

At the end of the research, it is noticed that the proposed method could locate the damage with no need to calculate the modal parameters; this could effectively reduce the time and cost of SHM through this method compared to other approaches to SHM. Hence, the proposed method provided an efficient, real-time, modal-free tool for damage detection of complex structures. This topic will be further studied by the authors in their future research under seismic loadings.

At this time, the proposed method is only verified for structures subjected to the moving load. Other type of excitations, such as seismic loading, will be considered in our future works.

Author Contributions: All the authors contributed to the research. H.K. conceived and designed the experiments. He, together with Y.-K.J., performed the laboratory models and recorded the data. Y.-Q.X. and X.-W.Y. guided the research and provided advice to ensure the accuracy of results. The paper was finally written by H.K. and confirmed by all the authors.

Acknowledgments: Special thanks to Zhejiang University, which supported this work, and provided financial sources (Cyrus Tang foundation in China and Natural Science Foundation of China (NSFC, No. 51178416)).

Conflicts of Interest: The authors declare no conflict of interest. The founding sponsors had no role in the design of the study; in the collection, analyses, or interpretation of data; in the writing of the manuscript; or in the decision to publish the results. 


\section{References}

1. Ibrahim, S.R. Random decrement technique for modal identification of structures. J. Spacecr. Rocket. 1977, 14, 696-700. [CrossRef]

2. Hester, D.; González, A. A wavelet-based damage detection algorithm based on bridge acceleration response to a vehicle. Mech. Syst. Signal Process. 2012, 28, 145-166. [CrossRef]

3. Balafas, K.; Kiremidjian, A.S. Development and validation of a novel earthquake damage estimation scheme based on the continuous wavelet transform of input and output acceleration measurements. Earthq. Eng. Struct. Dyn. 2015, 44, 501-522. [CrossRef]

4. Cantero, D.; Basu, B. Railway infrastructure damage detection using wavelet transformed acceleration response of traversing vehicle. Struct. Control Health Monit. 2015, 22, 62-70. [CrossRef]

5. Hester, D.; González, A. Impact of Road Profile when Detecting a Localised Damage from Bridge Acceleration Response to a Moving Vehicle. In Key Engineering Materials; Trans Tech Publications: Zürich, Switzerland, 2013; Volume 569, pp. 199-206.

6. Pnevmatikos, N.G.; Blachowski, B.; Hatzigeorgiou, G.D.; Swiercz, A. Wavelet analysis based damage localization in steel frames with bolted connections. Smart Struct. Syst. 2016, 18, 1189-1202. [CrossRef]

7. Pnevmatikos, N.G.; Hatzigeorgiou, G.D. Damage detection of framed structures subjected to earthquake excitation using discrete wavelet analysis. Bull. Earthq. Eng. 2016, 15, 1-22. [CrossRef]

8. González, A.; Hester, D. An investigation into the acceleration response of a damaged beam-type structure to a moving force. J. Sound Vib. 2013, 332, 3201-3217. [CrossRef]

9. Kordestani, H.; Xiang, Y.Q.; Ye, X.W. Output-Only Damage Detection of Steel Beam Using Moving Average Filter. Shock Vib. 2018, 13. [CrossRef]

10. Ku, C.J.; Cermak, J.E.; Chou, L.S. Random decrement based method for modal parameter identification of a dynamic system using acceleration responses. J. Wind Eng. Ind. Aerodyn. 2007, 95, 389-410. [CrossRef]

11. Buff, H.; Friedmann, A.; Koch, M.; Bartel, T.; Kauba, M. Design of a random decrement method based structural health monitoring system. Shock Vib. 2012, 19, 787-794. [CrossRef]

12. Yan, A.M.; De Boe, P.; Golinval, J.C. Structural damage diagnosis by Kalman model based on stochastic subspace identification. Struct. Health Monit. 2004, 3, 103-119. [CrossRef]

13. Yan, A.M.; Boe, P.D.; Golinval, J.C. Structural integral monitoring by vibration measurements. FM2003-Struct. Integr. Mater. Aging 2003, 4, 363-370.

14. Poncelet, F.; Kerschen, G.; Golinval, J.C.; Verhelst, D. Output-only modal analysis using blind source separation techniques. Mech. Syst. Signal Process. 2007, 21, 2335-2358. [CrossRef]

15. Kerschen, G.; Poncelet, F.; Golinval, J.C. Physical interpretation of independent component analysis in structural dynamics. Mech. Syst. Signal Process. 2007, 21, 1561-1575. [CrossRef]

16. Zhou, W.; Chelidze, D. Blind source separation based vibration mode identification. Mech. Syst. Signal Process. 2007, 21, 3072-3087. [CrossRef]

17. Chaojun, H.; Nagarajaiah, S. Experimental study on bridge structural health monitoring using blind source separation method: Arch bridge. Struct. Monit. Maint. 2014, 1, 69-87. [CrossRef]

18. Cole, J.R.H. On-the-line analysis of random vibrations. In Proceedings of the 9th Structural Dynamics and Materials Conference, Palm Springs, CA, USA, 1-3 April 1968. [CrossRef]

19. Liu, C.; Teng, J.; Liu, J. Improvement of the decentralized random decrement technique in wireless sensor networks. In Proceedings of the 2014 Word Congress on Advance in Civil, Environmental, and Materials Research (ACEM14), Busan, Korea, 24-28 August 2014.

20. Vandiver, J.K.; Dunwoody, A.B.; Campbell, R.B.; Cook, M.F. A Mathematical Basis for the Random Decrement Vibration Signature Analysis Technique. J. Mech. Des. 1982, 104, 307-313. [CrossRef]

21. Ibrahim, S.R.; Asmussen, J.C.; Brincker, R. Vector triggering random decrement for high identification accuracy. J. Vib. Acoust. 1998, 120, 970-975. [CrossRef]

22. Ibrahim, S.R. Efficient random decrement computation for identification of ambient responses. In Proceedings of the SPIE, the International Society for Optical Engineering, Kissimmee, FL, USA, 5-8 February 2001; Volume 4359.

23. Asayesh, M.; Khodabandeloo, B.; Siami, A. A random decrement technique for operational modal analysis in the presence of periodic excitations. Proc. Inst. Mech. Eng. Part C J. Mech. Eng. Sci. 2009, 223, 1525-1534. [CrossRef] 
24. Rodrigues, J.; Brincker, R. Application of the Random Decrement Technique in Operational Modal Analysis. In Proceedings of the 1st International Operational Modal Analysis Conference, Copenhagen, Denmark, 26-27 April 2005; pp. 191-200.

25. Lee, J.W.; Kim, J.D.; Yun, C.B.; Yi, J.H.; Shim, J.M. Health-monitoring method for bridges under ordinary traffic loadings. J. Sound Vib. 2002, 257, 247-264. [CrossRef]

26. Lin, C.S.; Chiang, D.Y. Modal identification from non-stationary ambient response data using extended random decrement algorithm. Comput. Struct. 2013, 119, 104-114. [CrossRef]

27. He, X.H.; Hua, X.G.; Chen, Z.Q.; Huang, F.L. EMD-based random decrement technique for modal parameter identification of an existing railway bridge. Eng. Struct. 2011, 33, 1348-1356. [CrossRef]

28. Wu, W.H.; Chen, C.C.; Liau, J.A. A multiple random decrement method for modal parameter identification of stay cables based on ambient vibration signals. Adv. Struct. Eng. 2012, 15, 969-982. [CrossRef]

29. Sim, S.H.; Jo, H.; Carbonell-Márquez, J.F.; Spencer, B.F.; Jo, H. Decentralized random decrement technique for data aggregation and system identification in wireless smart sensor networks. Probab. Eng. Mech. 2011, 26, 81-91. [CrossRef]

30. Jeary, A.P. The description and measurement of nonlinear damping in structures. J. Wind Eng. Ind. Aerodyn. 1996, 59, 103-114. [CrossRef]

31. Xiang, Y.Q.; Ye, X.W.; Zhang, L.C.; He, X.Y. Structural health monitoring system of steel-tube arch bridge: Design and implementation of a teaching demonstration platform. In Proceedings of the 6th International Conference on Structural Health Monitoring of Intelligent Infrastructure, Hong Kong, China, 9-11 December 2013.

32. Arias, A. Measure of earthquake intensity. In Massachusetts Institute of Technology; University of Chile: Santiago, Chile, 1970.

(C) 2018 by the authors. Licensee MDPI, Basel, Switzerland. This article is an open access article distributed under the terms and conditions of the Creative Commons Attribution (CC BY) license (http:/ / creativecommons.org/licenses/by/4.0/). 